\title{
Variability and Grouping of Northwestern Spanish Chestnut Cultivars. I. Morphological Traits
}

\author{
S. Pereira-Lorenzo \\ Departamento de Ingeniería Agroforestal y Producción Vegetal, Universidad de Santiago de Compostela, \\ Campus de Lugo, 27002 Lugo, Spain \\ J. Fernández-López \\ Centro de Investigaciones Forestales de Lourizán, Apartado 127, 36080 Pontevedra, Spain
}

J. Moreno-González

Centro de Investigaciones Agrarias de Mabegondo, Apartado 10, 15080 La Coruña, Spain

Additional index words. Castanea sativa, principal component analysis, cluster analysis, germplasm, fruit breeding

\begin{abstract}
Different chestnut (Castanea sativa Mill.) cultivars are at present grown in the region of Galicia, northwestern Spain, but no distinguishing traits among cultivars have been defined so far. The objectives of this research were to 1) describe the intra and intercultivar variability of chestnut cultivars; 2) define primary morphological traits to be useful for a simple morphological classification system of the cultivars; and 3) study the association between some environmental variables and the morphological traits. Seventeen morphological traits in a sample of 373 trees belonging to 82 local cultivars of chestnut were studied by methods of numerical taxonomy, principal component and cluster analysis. These traits were selected from 135 previously studied as having possible discriminating taxonomic value. Significant variability among cultivars and among trees within cultivars was found for most of the traits. The trees were grouped according to the degree of dissimilarity on the basis of the Mahalanobis generalized distance. Most of the clones collected under a specific cultivar name were included within the same cluster group enabling us to classify 53 of the cultivars studied. A hierarchical classification system that identifies eight cultivar groups is proposed based on four discriminating levels: nut size, fruit shape, male flower type and length of burr spines. Most of the correlations between the environmental variables and the morphological traits were no significant or had a low value. The lack of correlation between the environmental variables and nut size indicates that this important trait is under strong genetic control, it is not influenced by environmental conditions and it is consistent throughout the area sampled.
\end{abstract}

Chestnut (Castanea sativa) in the northwestern part of Spain, the region of Galicia, occupies an area of 28,689 ha (Ministerio de Agricultura, Pesca y Alimentación, 1980), accounting for about $50 \%$ of the chestnut production in Spain. Most chestnut groves are grafted with nut cultivars, and in some areas there are dual purpose cultivars for nut and timber. Chestnuts have been grown in this region since the Middle Ages, and some of the current cultivar names date from that era (Justo and Almez, 1991).

The genetic improvement of chestnut as a nut crop in Spain started 50 years ago to develop hybrid rootstocks resistant to ink disease (Phytophthora spp.), a widespread disease to which European chestnut (C. sativa) is very sensitive (Fernández et al., 1993). Nevertheless, some of the European chestnut groves escaped the disease, particularly those located in the cooler and higher-altitude areas. Local $C$. sativa cultivars survived as grafted trees on seedlings, and they are the current basis of chestnut production and have not been subjected to a genetic study (Fernández, 1984, 1986, 1987). However, the inventory and distribution of the local cultivars has already been studied (Fernández and Pereira, 1993). Onehundred and forty-three different cultivar names have been listed, but no distinguishing traits among cultivars have been defined. Similarly, neither the existence of presumed synonymy nor the variability within the cultivars has been analyzed.

Received for publication 8 June 1995. Accepted for publication 9 Oct. 1995. Part of a thesis submitted by S. Pereira-Lorenzo as requirement for the PhD degree, Universidad Politécnica de Madrid. This research was funded in part by the INIA and the Dirección Xeral de Montes (Xunta de Galicia). The cost of publishing this paper was defrayed in part by the payment of page charges. Under postal regulations, this paper therefore must be hereby marked advertisement solely to indicate this fact.
Previous work on characterizing and identifying chestnut cultivars primarily is based on the studies of Breviglieri (1955), although classification work was accomplished by Chenet (1983). Attempts to characterize chestnut cultivars also should consider the descriptors developed by the International Union for the Protection of New Varieties of Plants (UPOV, 1988). To date, numerical taxonomy methods have not been applied to the morphological classification of chestnut cultivars. Multivariate analysis has been used for perennial fruit species to study germplasm of apricot (Pérez-Gonzales, 1992), peach (Pérez et al., 1993), and sour cherry (Hilling and Iezzoni, 1988). This technique has also been used to study variability in crop species such as Lolium perenne (Oliveira and Charmet, 1992), maize (Goodman and Bird, 1977; Llauradó and Moreno-González, 1993), Phaseolus vulgaris (Martin and Adams, 1987), and finger millet (Hussaini et al., 1977). The assessment of the existing intra and intercultivar genetic variability will be very useful to decide how to conduct clonal selection programs of chestnut trees.

The objectives of this study were to 1) describe the intra and intercultivar variability of Galician chestnut cultivars; 2) define primary morphological traits useful for a simple morphological classification system of the cultivars; and 3) study the association between some environmental variables and the morphological traits.

\section{Materials and Methods}

Germplasm sampling. From 1989 to 1991, 373 trees were sampled, of which 358 were said to belong to 82 cultivars, with name of the cultivar being unknown in the remaining 15 (Table 1). The sampling was conducted in areas where information was available with regard to the existence of local cultivars (Fernández 
and Pereira, 1993). The trees were located at altitudes varying from 140 to $1060 \mathrm{~m}$ above sea level, the latter being considered the upper limit for growing chestnut trees for nut production in Galicia. Only one tree per existing cultivar was sampled at each site location. More than one tree was collected for 50 cultivars; the remaining 31 cultivars were found in only one area because of their small area of distribution. Most of these trees were introduced in the Centro de Investigaciones Forestales de Lourizán(CIFL), Pontevedra, Spain, where they were grafted on to the hybrid rootstock 'HS'.

Morphological traits. Cultivars are usually studied in collections that reduce the environmental variance, however in situ evaluation can be an option for tree species with a late bearing tendency, such as chestnut. This work studied some traits in the field and others in collection. Of 135 traits recorded in preliminary studies (Pereira, 1994), the 17 that showed a greater discrimination between cultivar were chosen for further study (Table 2). Fourteen were quantitative and three were qualitative and were scored as class variables. The quantitative and qualitative variables can be used for classification analysis as suggested by Kaufman and Rosseeuw (1990) and Rubin (1967). These two types of variables were used for principal component analysis in peach (Perez et al., 1993). Kaufman and Rosseeuw (1990) also pointed out that a new binomial variable can be created for each of the classes of qualitative traits, where the values 1 or 0 indicate presence or absence of the observed quality in the individual phenotype being recorded. Thus, the three qualitative traits were split up in ten binomial

Table 1. List of cultivars sampled for study from Galicia, Spain. Some unknown trees have been included in this study because they are grafted and are of interest for nut production in their origin areas.

\begin{tabular}{|c|c|c|c|c|c|}
\hline No. & Cultivar & No. trees & No. & Cultivar & No. trees \\
\hline 3 & Abadá & 3 & 45 & Palmeiros & $--^{z}$ \\
\hline 2 & Abarcá & 1 & 46 & Paradesa & 1 \\
\hline 3 & Amadengue & 1 & 47 & De Parede & 16 \\
\hline 4 & Amarelante & 25 & 48 & Patacuda & 1 \\
\hline 5 & Anaxa & 1 & 49 & Pelada & 5 \\
\hline 6 & Das Anchas & 1 & 50 & Peluda & 1 \\
\hline 7 & Areal & 2 & 51 & Picona & 2 \\
\hline 8 & Berciana & 1 & 52 & Porteliña & 2 \\
\hline 9 & Bermella & 5 & 53 & Portuguesa & 2 \\
\hline 10 & Blanca & 17 & 54 & Pozoredondo & 4 \\
\hline 11 & Bolesas & 1 & 55 & Praga d'Afora & 4 \\
\hline 12 & Bravo de Leirado & 5 & 56 & Praga do Bolo & 5 \\
\hline 13 & Burgaceira & 2 & 57 & De Presa & 9 \\
\hline 14 & Cabezuda & 3 & 58 & De Puga & 1 \\
\hline 15 & Calvas & 4 & 59 & Puga do Receiro & 1 \\
\hline 16 & Campilla & 3 & 60 & Raigona & 16 \\
\hline 17 & Carrelaos & 1 & 61 & Rañuda & 1 \\
\hline 18 & Castelás & 1 & 62 & Rapada & 18 \\
\hline 19 & Caurelal & 1 & 63 & Redondo & 1 \\
\hline 20 & De Cedo & 2 & 64 & Riá & 2 \\
\hline 21 & Cerreda & 2 & 65 & Ribeirá & 1 \\
\hline 22 & Courelá & 8 & 66 & Rosendas & 1 \\
\hline 23 & Culona & 4 & 67 & Rozada & 1 \\
\hline 24 & Curuxa & 1 & 68 & Salnesa & 5 \\
\hline 25 & Desgrañadiza & 2 & 69 & Sergude & 2 \\
\hline 26 & Famosa & 16 & 70 & Serodia & 6 \\
\hline 27 & Galega & 2 & 71 & Soutogrande & 1 \\
\hline 28 & Garrida & 7 & 72 & Tarabelao & 1 \\
\hline 29 & Garriga & 1 & 73 & Temperá & 9 \\
\hline 30 & Horrón & 2 & 74 & Torbeana & 2 \\
\hline 31 & Inxerta & 10 & 75 & Toubesa & 1 \\
\hline 32 & Da Lebre & 3 & 76 & Veiguiña & 1 \\
\hline 33 & De Lemos & 4 & 77 & Ventura & 8 \\
\hline 34 & Longal & 9 & 78 & Verde & 17 \\
\hline 35 & Loura & 12 & 79 & Vileta & 2 \\
\hline 36 & Luguesa & 12 & 80 & Villarenga & 1 \\
\hline 37 & Mazaíño & 1 & 81 & Xábrega & 7 \\
\hline 38 & De San Miguel & 1 & 82 & Xilimendra & 1 \\
\hline 39 & Monfortina & 1 & & & \\
\hline 40 & Negral, Queiroguesa & 13 & & Unknown cultivars & \\
\hline 41 & Ouriza & 3 & & Sampling place & \\
\hline 42 & Outeira & 2 & & Bolo & U1 \\
\hline 43 & País & 2 & & Cerdedo & $\mathrm{U} 2, \mathrm{U} 3, \mathrm{U} 4$ \\
\hline 44 & Pallarego & 1 & & Ponteareas & U5 to U15 \\
\hline
\end{tabular}

${ }^{\mathrm{z} N o t}$ included in the analysis. 
Table 2. Quantitative and qualitative traits evaluated in this study.

\begin{tabular}{|c|c|c|}
\hline Trait symbol & \multicolumn{2}{|c|}{ Trait description } \\
\hline \multicolumn{3}{|c|}{ Quantitative traits } \\
\hline LNT & \multicolumn{2}{|c|}{ Lateral nut thickness $(\mathrm{cm})^{\mathrm{z}}$. } \\
\hline LNW & \multicolumn{2}{|c|}{ Lateral nut width $(\mathrm{cm})^{\mathrm{z}}$. } \\
\hline TWL & \multicolumn{2}{|c|}{ Total weight of the lateral nuts $(\mathrm{g})$. } \\
\hline NHS & \multicolumn{2}{|c|}{ Nut hilum surface $\left(\mathrm{cm}^{2}\right)^{\mathrm{z}}$. } \\
\hline WLR & \multicolumn{2}{|c|}{$100 \times \mathrm{LNW} \mathrm{LNL}^{\mathrm{y}}$ (width to length rati } \\
\hline TLR & \multicolumn{2}{|c|}{$100 \times$ LNT/LNL $^{y}$ (thickness to length $r$} \\
\hline NNK & \multicolumn{2}{|c|}{ Number of nuts per kilogram ${ }^{2}$. } \\
\hline $\mathrm{C} 24$ & \multicolumn{2}{|c|}{ Percentage of nuts with diameter $<24 n$} \\
\hline $\mathrm{C} 28$ & \multicolumn{2}{|c|}{ Percentage of nuts with diameter 24 to } \\
\hline $\mathrm{C} 32$ & \multicolumn{2}{|c|}{ Percentage of nuts with diameter 29 to } \\
\hline $\mathrm{C} 36$ & \multicolumn{2}{|c|}{ Percentage of nuts with diameter 33 to } \\
\hline $\mathrm{C} 40$ & \multicolumn{2}{|c|}{ Percentage of nuts with diameter 37 to } \\
\hline NIL & \multicolumn{2}{|c|}{ Number of incisions on the left side of } \\
\hline DSN & \multicolumn{2}{|c|}{$\begin{array}{r}\text { Distance between secondary nerves of } \\
\text { Qualitative traits }\end{array}$} \\
\hline BTS, BTM, BTL & \multicolumn{2}{|c|}{ Size of burr spines: short, middle, and 1} \\
\hline CAS, CBR, CME, CLO & \multicolumn{2}{|c|}{ Type of catkin: astaminate, brachystami } \\
\hline TSW, TTL, TBI & \multicolumn{2}{|c|}{ Chestnut taste: sweet, tasteless and bitt } \\
\hline \multicolumn{3}{|c|}{$\begin{array}{l}\text { zTraits recommended by the UPOV (1988) for the classification of culti } \\
\text { yLNL = lateral nut length. }\end{array}$} \\
\hline \multicolumn{3}{|c|}{$\begin{array}{l}\text { Table 3. F values from the analysis of variance of several morphological } \\
\text { traits for the sources of variation cultivar and tree within cultivar. }\end{array}$} \\
\hline & \multicolumn{2}{|c|}{ Source of variation } \\
\hline Trait & Cultivar & Tree/cultivar \\
\hline$\overline{\mathrm{LNT}}$ & $2.53^{* *}$ & $1.93^{* *}$ \\
\hline LNW & $2.08^{* *}$ & $2.74^{* *}$ \\
\hline TWL & $1.46^{\mathrm{NS}}$ & $2.25^{* *}$ \\
\hline NHS & $7.64^{* *}$ & $3.37^{* *}$ \\
\hline WLR & $4.18^{* *}$ & $2.01^{* *}$ \\
\hline TLR & $4.01^{* *}$ & $1.61^{* *}$ \\
\hline NNK & $2.26^{* * *}$ & $2.90^{* *}$ \\
\hline $\mathrm{C} 24$ & $1.98^{* *}$ & $2.59^{* *}$ \\
\hline C28 & $1.88^{* *}$ & $1.75^{* *}$ \\
\hline $\mathrm{C} 32$ & $2.33^{* * *}$ & $2.52^{* *}$ \\
\hline C36 & $2.79^{* * *}$ & $1.31^{*}$ \\
\hline $\mathrm{C} 40$ & $1.86^{* *}$ & $2.41^{* * *}$ \\
\hline
\end{tabular}

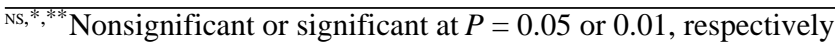

Table 4. Estimates of genetic variances ${ }^{\mathrm{z}}$ for the cultivars and trees within cultivars in several morphological traits.

\begin{tabular}{lcccc}
\hline \hline & \multicolumn{4}{c}{ Genetic variances \pm associated error } \\
\cline { 2 - 5 } Trait & Cultivar & \pm Error & Tree/cultivar & \pm Error \\
\hline LNT & 0.01 & 0.002 & 0.01 & 0.003 \\
LNW & 0.03 & 0.005 & 0.03 & 0.006 \\
TWL & 1.63 & 0.53 & 2.10 & 0.59 \\
NHS & 0.59 & 0.11 & 0.23 & 0.08 \\
WLR & 17.72 & 4.90 & 26.14 & 4.16 \\
TLR & 17.72 & 2.63 & 4.16 & 2.27 \\
NNK & 364.21 & 74.48 & 443.00 & 26.01 \\
C24 & 139.09 & 31.21 & 200.72 & 67.34 \\
C28 & 141.85 & 34.49 & 112.68 & 38.00 \\
C32 & 167.71 & 34.61 & 93.31 & 29.55 \\
C36 & 8.56 & 1.89 & 5.10 & 2.18 \\
C40 & 7.80 & 1.97 & 11.0 & 2.24
\end{tabular}

$\overline{{ }^{\mathrm{Z}} \text { Genetic variances were biased upward, because genetic and location }}$ effects were confounding. variables (Table 2). Seven of the characters studied have been recommended by UPOV (1988) to determine distinction, homogeneity, and stability of chestnut cultivars.

Environmental variables. Four additional variables associated with the climatic conditions of the sampling place were defined for each individual. One variable was the effective thermal index (ETI) defined as the accumulated temperature degrees $\left({ }^{\circ} \mathrm{C}\right)$ above seven between budbreak and harvesting time using average temperatures by month (Hidalgo, 1980); the others were the accumulated rainfall from April to October (RAO) and from July to October (RJO). These variables were computed for the meteorological station nearest the place of sampling for each of the 373 individuals. A reasonable coverage of meteorological stations exist in the sampled area. In addition, the altitude (ALT) of each sampling place was also noted for the appropriate tree.

Statistical analyses. An analysis of variance (ANOVA) was conducted to determine the effects of the cultivar and tree within cultivar. The procedure PROC GLM of SAS for unbalanced data was used to analyze the 3 years $(1989,1990$, and 1991) data of the following quantitative variables: lateral nut thickness (LNT), lateral nut width (LNW), total weight of lateral nuts (TWL), width to length ratio (WLR $=100 \times \mathrm{LCW} /$ length), thickness to length ratio $(\mathrm{TLR}=100 \times \mathrm{TCL} /$ length), nut hilum surface $(\mathrm{NHS})$, nut number per kilogram (NNK), and percentage of nuts with diameter <24 mm (C24), 24-28 mm (C28), 29-32 mm (C32), 33-36 mm (C36), and 37-40 $\mathrm{mm}$ (C40) (Table 2), according to the following model:

$$
\mathrm{X}_{\mathrm{i}(\mathrm{m}) \mathrm{jk}}=\mu+\mathrm{C}_{\mathrm{m}}+\mathrm{T}_{\mathrm{i}(\mathrm{m})}+\mathrm{Y}_{\mathrm{j}}+(\mathrm{CY})_{\mathrm{mj}}+(\mathrm{TY} / \mathrm{C})_{\mathrm{i}(\mathrm{m}) \mathrm{j}}+\epsilon_{\mathrm{i}(\mathrm{m}) \mathrm{jk}}
$$

where $\mathrm{X}_{\mathrm{i}(\mathrm{m}) \mathrm{k}}$ is the observation of the tree $i(i=1$ to 26) within the cultivar $m(m=1$ to 82$)$ in the year $j(j=1,2,3)$ and the sample $k(k$ $=1$ to 10$) ; \mu$ is the mean of all the observations; $\mathrm{C}_{\mathrm{m}}, \mathrm{T}_{\mathrm{i}(\mathrm{m})}, \mathrm{Y}_{\mathrm{j}},(\mathrm{CY})_{\mathrm{mi}}$, $(\mathrm{TY} / \mathrm{C})_{\mathrm{i}(\mathrm{m}) \mathrm{j}}$, and $\in_{\mathrm{i}(\mathrm{m}) \mathrm{jk}}$ are the effects of the cultivar $m$, the tree $i$ within the cultivar $m$, the year $j$, the interaction cultivar $\times$ year, the interaction tree within cultivar $\times$ year, and the error associated to the sample $k$ in the observation $i(m) j k$, respectively.

All effects are assumed to be random. Then, the error terms for 
Table 5. Eigen values associated to the first nine principal components (PCs) estimated from the correlation matrix of 14 quantitative traits and 10 qualitative variables. Pearson correlation coefficients between environmental variables and the PC.

\begin{tabular}{lccccccccc}
\hline \hline & PC1 & PC2 & PC3 & PC4 & PC5 & PC6 & PC7 & PC8 & PC9 \\
\hline Eigen value & 6.251 & 2.965 & 2.120 & 1.872 & 1.671 & 1.437 & 1.337 & 1.186 & 1.010 \\
Accumulated variance (\%) & 26.1 & 38.4 & 47.2 & 55.0 & 62.0 & 68.0 & 73.6 & 78.5 & 82.7 \\
Pearson correlation between climatic variables and the PC & & & & & & \\
ALT & NS & -0.14 & NS & NS & -0.26 & NS & 0.30 & NS & NS \\
ETI & NS & 0.13 & -0.14 & NS & 0.15 & NS & NS & NS & NS \\
RAO & NS & NS & NS & NS & NS & NS & -0.15 & NS & NS \\
RJO & NS & NS & 0.15 & NS & NS & NS & -0.20 & -0.14 & NS \\
\hline
\end{tabular}

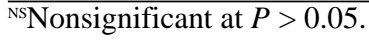

testing the significance of the mean squares for cultivars and trees within cultivars are the cultivar $\times$ year and the tree within cultivar $\times$ year interactions, respectively.

The genetic variances of the cultivars and of trees within cultivars for 12 quantitative traits observed in 3 years were estimated from the corresponding variance components in the expected mean squares of the ANOVA, when random effects were considered. The errors associated with these variances were estimated according to Kempthorne (1969). Since there is not replication of trees in different locations, the genetic variance for trees within cultivars is biased upward because of confounding of genetic and location effects.

A principal components analysis (PCA) on the correlation matrix of the clone means of the 17 traits was carried out using the procedure PRINCOMP of SAS to study the similarity degree among cultivars. Moreover, the variable grouping of the related variables was studied by the procedure VARCLUS of SAS. In addition, the correlations between the first PC extracted and the climatic variables previously defined were calculated.

The Mahalanobis generalized distance ( $\mathrm{D}^{2}$ of Mahalanobis) (Goodman, 1972, 1973) was calculated as a dissimilarity measure between clones. This distance was computed from the standardized PCs that had Eigen values higher than $1\left(\lambda_{k}>1\right)$. A cluster analysis (UPGMA) (Sneath and Sokal, 1973) was carried out on the distance matrix to help with the interpretations among populations.

\section{Results and Discussion}

Significant differences among cultivars were found for all the studied characteristics except for the total weight of the lateral chestnuts (Table 3). Similarly, there were significant differences among trees within cultivars for all the traits. Therefore, there was significant phenotypic variability within and between cultivars.

The estimates of genetic variances of cultivars and trees within cultivars were significant for all traits except for nut hilum surface (NHS) within cultivars (Table 4). These genetic variances of cultivars and trees within cultivars were not significantly different from each other for most traits, except for nut hilum surface (NHS) and thickness to length ratio (TLR) (Table 4). Therefore, there are intercultivar variability, but the intracultivar variability is also important. The intra and intercultivar variability found in this study concurs with the results found by Borghetti et al. (1983) and Bassi and Sbaragli (1984) in some Italian cultivars. From the point of view of selection, it will be necessary to exploit both types of genetic variability. The ANOVA was not able to separate the variability due to genetic and location effects. Thus, the genetic variances were biased upward because of confounding of genetic and location effects. However, the genetic effects are expected to be more important than the location effects for the traits studied because either no significant or very low correlations between morphological traits and environmental variables were found (Tables 5 and 6). Therefore, the bias in the estimation of genetic variances is expected not to be very important. The study with isoenzymes confirms these results of genetic variability (Pereira et al., 1995).

Nine PCs had Eigen values higher than 1 and accounted for 83 $\%$ of the variation (Table 5). The characteristics referring to nut size were the most important in the first PC, with the $26.1 \%$ of the variance. The chestnut shape indexes (WLR and TLR) had the greatest importance in the second PC and accounted for $12.3 \%$ of the variation. Chestnut sweetness was the primary variant in the third PC (8.8\% of the variation). The burr spine length had influence especially on the fourth PC, with the $7.8 \%$ of the variance. The mesostaminate and longistaminate catkin types had a greater influence in the fifth PC ( $7 \%$ of the variation), whereas the brachystaminate type together with the calibre $28 \mathrm{~mm}(\mathrm{C} 28)$ and taste had the greatest influence in the sixth PC (6\% of the variation). The number of incisions of leaf margin (NIL) and the longistaminate, astaminate and brachystaminate catkin types strongly influenced the seventh PC, accounting for 5.6\% of the variation. The distance between secondary nerves of the leaf limb (DSN), as well as the NIL and the 28-mm-diameter nuts (C28), were the most important contributors to the eighth PC (4.9\% of the variation). Finally, the astaminate and brachystaminate catkins, together with the thorn length of type BTL, influenced the ninth PC, accounting for $4.2 \%$ of the variation.

No significant Pearson correlations were found between the first $\mathrm{PC}$ and the environmental variables, which seems to indicate that the

Table 6. Significant Pearson correlations $(P<0.05)$ between altitude (ALT), effective thermal integral (ETI), rainfall from April to October (RAO) and from July to October (RJO), and the studied morphological traits.

\begin{tabular}{|c|c|c|c|c|}
\hline Trait & ALT & ETI & RAO & RJO \\
\hline \multicolumn{5}{|c|}{ Quantitative traits } \\
\hline TWL & NS & NS & 0.15 & NS \\
\hline WLR & NS & NS & -0.15 & NS \\
\hline TLR & -0.20 & NS & NS & NS \\
\hline NNK & -0.12 & NS & -0.11 & NS \\
\hline NIL & -0.21 & 0.21 & NS & NS \\
\hline \multicolumn{5}{|c|}{ Qualitative traits } \\
\hline BTL & 0.11 & NS & NS & NS \\
\hline CAS & NS & NS & NS & 0.13 \\
\hline CBR & 0.13 & NS & NS & -0.25 \\
\hline CME & 0.14 & -0.20 & NS & NS \\
\hline CLO & -0.35 & 0.16 & NS & 0.12 \\
\hline TSW & NS & NS & -0.13 & -0.17 \\
\hline TTL & NS & NS & 0.11 & 0.14 \\
\hline
\end{tabular}

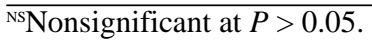




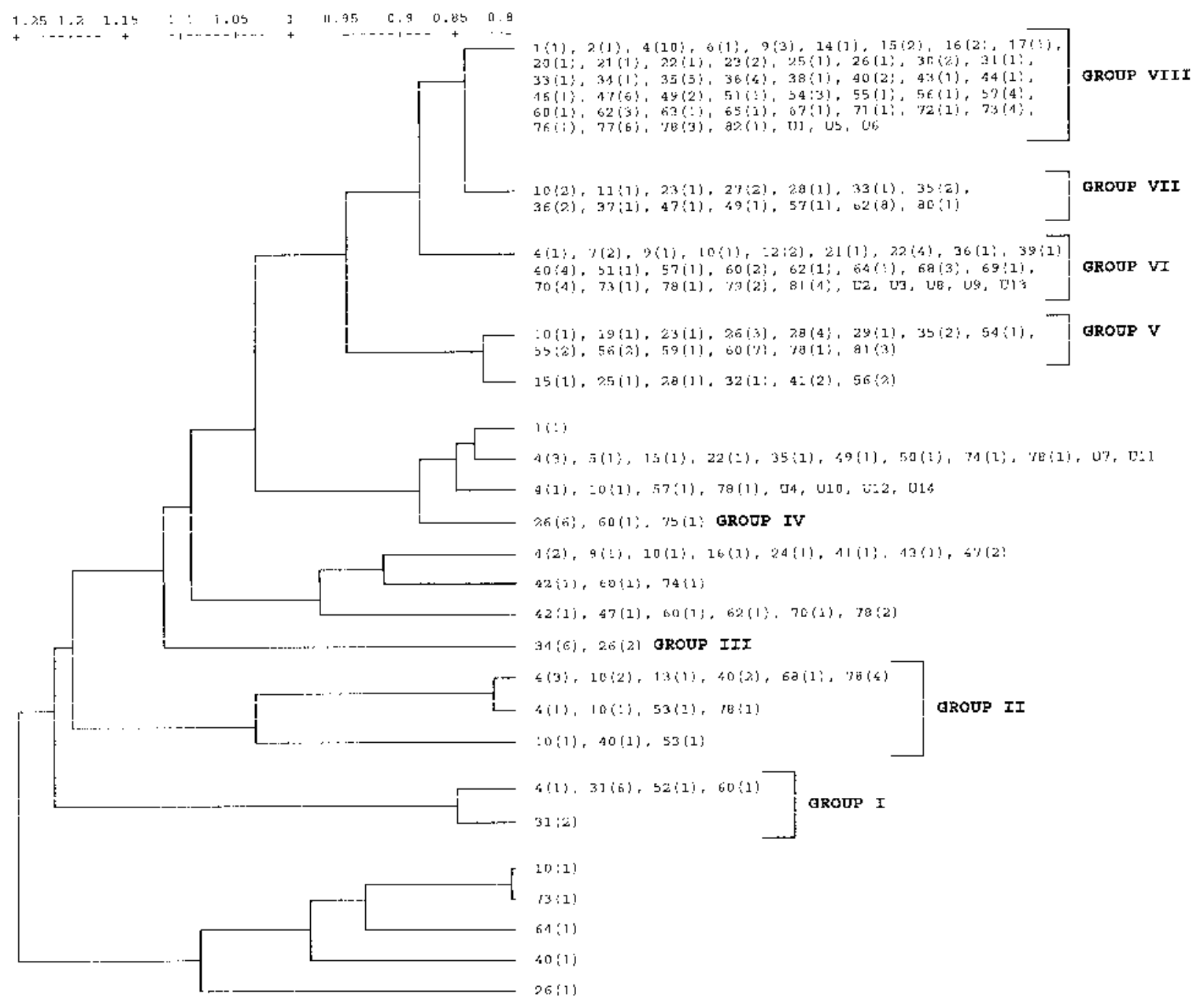

Fig. 1. Average linkage dendrogram of 296 trees corresponding to 75 cultivars of chestnut from northwestern Spain based on the Mahalanobis' generalized distance of morphological data. In brackets are the number of trees belonging to the same cultivar.

nut size characteristics are independent of the local climate, and therefore favorable and unfavorable characteristics of the nut can be found in any climatic situation (Table 5). The second and eighth PCs are only slightly correlated to some environmental variables. Taste might be associated with moisture, since sweetness was a strong component of the third PC and it was significantly correlated with rainfall. The fifth and seventh PCs are only slightly correlated to some environmental variables what may be due to low correlations between these variables and the male flower type.

Correlations between the individual morphological and the environmental variables are generally low (Table 6), suggesting that the environmental conditions might have not greatly influenced the natural selection of the studied morphological traits. However, sweetness is slightly associated with lower rainfall, while longistaminate catkins, higher thickness to length ratio, higher number of incisions of the leaf are all weakly associated with lower altitudes.

The UPGMA cluster analysis carried out on 296 trees due to some missing values produced the following tree groupings around the cultivar denomination when the dendogram is cut at a Mahalanobis distance of 0.8 (Fig. 1).

Group I clearly separates eight of the nine trees studied in the 'Inxerta' cultivar, although other trees are also included in this group. Characteristics that define the group are large nut size, low shape indexes $(100<$ WLR < 110, and TLR < 66), mesostaminate catkins, low number of incisions on the leaf (NIL < 12), and high distance between the secondary nerves of the leaf limb (DSN > 1 $\mathrm{cm})$. Group II is formed by trees of 'Amarelante', 'Blanca', 'Negral', 'Portuguesa', and 'Verde' with characteristics of astaminate catkins. Group III differentiates six of the seven trees of 'Longal', which is characterized by low shape index (triangular chestnuts, WLR < 100), brachystaminate catkins, long spines, and sweet taste. Group IV incorporates six out of ten trees of 'Famosa', whose most important characteristics are long burr spines and brachystaminate catkins, elliptical shape $(110<\mathrm{WLR}<120)$, and big chestnuts (TWC $>13 \mathrm{~g}$ ). Group V comprises four trees of 'Garrida', two of 'Praga d'Afora', two of 'Praga do Bolo', seven of 'Raigona', and three of 'Xabrega' with brachystaminate catkins and middle burr thorns. Group VI includes 'Courelá', 'Negral', 'Salnesa', 'Serodia', 'Xabrega', and 'Vileta' with longistaminate catkins; a similar group has also been formed by isoenzyme analysis (Pereira et al., 1995). Group VII includes 'Rapada' (8 out of 14 clones) with short burr spines, a cultivar that owes its name to this fact. Group VIII contains the most of trees belonging to 'Amarelante' (10 of 22), 'Bermella' (3 of 5 clones), 'Loura' (5 of 10 clones), 'Luguesa' (4 of 12 clones), 'Parede' (6 of 10 clones), 
Table 7. Suggested system of classification of the primary Galician chestnut cultivars by morphological traits according to UPGMA cluster analysis.

\begin{tabular}{lcccc}
\hline \hline \multicolumn{4}{c}{ Discrimination level and type of discriminating trait } & \\
\hline 1 & 2 & 3 & 4 \\
\hline Nut size & Nut shape & Male flowering & Burr spine length & Group \\
\hline$<80$ nuts/kg & $100<$ WLR $<110$ & Mesostaminate & Medium (BTM) \\
$80 \%$ nuts $>32 \mathrm{~mm}$ & Elliptical-triangular & & & I \\
$>80$ nuts $/ \mathrm{kg}$ & WLR $>110$ & Astaminate & Medium (BTM) or Short (BTS) & II \\
$80 \%$ nuts $<32 \mathrm{~mm}$ & WLR $<100$ & Brachystaminate & Long (BTL) & III \\
& Triangular & Brachystaminate & Long (BTL) & IV \\
& WLR $>100$ & Brachystaminate & Medium (BTM) & V \\
& & Longistaminate & Medium (BTM) & VI \\
& & Mesostaminate & Short (BTS) & VII \\
& & & Medium (BTM) & VIII \\
\hline
\end{tabular}

${ }^{\mathrm{z}}$ See Fig. 1.

'Pozoredondo' (3 of 4 clones), 'Presa' (4 of 6 clones), 'Temporá' ( 4 of 5 clones), and 'Ventura' ( 6 of 6), which have mesostaminate catkins and intermediate spine length.

Most of the trees collected under a specific cultivar name were included within the same cluster group. In fact, among the 164 trees corresponding to the 21 cultivars with five or more sampled trees, an average of $69 \%$ of the trees was assigned to the same cluster group and another 23\% was included in another group. Therefore, the trees recognized under a cultivar name generally have common characteristics. However, there is a low percentage of trees classified as a specific cultivar that are scattered among other groups and do not share the specific traits with the majority of trees sampled from the cultivar. This can be due to either a misnaming of the clone or an occasional use of sexual propagation. Different cultivar names that fall in the same group could be considered as synonymous, if they do not show genetic differentiation either morphological or isoenzymic differences (Pereira et al., 1995). The unknown cultivars could be assigned to different groups (Fig. 1), however the different allelic composition has not permitted to identify them with the studied cultivars (Pereira et al., 1995).

The reduction of the number of traits from 135 in the previous work of Pereira (1994) to 17 in this work has enabled us to study the intra and intercultivar variability of the clones and their grouping at a Mahalanobis distance of 0.8 . The association of the groups with the most important cultivars justifies continuing the use of the term cultivar, since the specific differential traits can be vegetatively propagated through grafting. The most discriminating characteristics has been nut size (calibre), shape index, flowering, and spine length.

Four main cluster of variables were obtained by the procedure VARCLUS. Cluster 1 includes variables that describe nut size and catkins (TCL, LCW, TWL, CHS, NNK, C24, C32, CMO, CLO); cluster 2 includes variables referring to nut size, nut shape, leaves, and catkins (C28, C36, C40, TBI, WLR, TLR, NIL, DSN, CAS); cluster 3 variables describe nut taste and catkins (TTL, TSW, CBR); and cluster 4 variables are related to burr spines (BTS, BTM, BTL). This classification system concurs with the trends shown in the PC analysis and the UPGMA classification.

\section{Conclusions}

A classification based on easily recognizable characteristics by farmers can be drawn from the results. Four hierarchical levels are suggested: level 1 is determined by the nut size; level 2 by the shape index (the width to length ratio, WLR); level 3 by the type of male flowering; and level 4 by the burr spine length. These levels give rise to eight classes (Table 7) that correspond to the clone groups of the main cultivars that the UPGMA cluster analysis recognized. This method of numerical taxonomy enables classification of 53 of the 82 cultivars studied (Pereira et al., 1995). The other 28 cultivars show greater variability within than between cultivars and so they cannot be classified. The origins of this variation could be attributed to mistakes in grafting, or in naming the cultivar, or occasional use of sexual propagation. The lack of correlation between the environmental variables and nut size indicates that this important trait is under strong genetic control, is not influenced by environmental conditions and is consistent throughout the area sampled.

The characterization and introduction of this material in the chestnut collection of CIFL will allow immediate propagation of the clones with specific characteristics for the desired purposes. The suggested selection strategy is to select individual clones among and within cultivars to exploit both the intra and intercultivar genetic variability.

\section{Literature Cited}

Bassi, D. and E. Sbaragli. 1984. Indagine pomologica su alcuni cloni di castagno da frutto (C. sativa Mill.). Frutticoltura 6/7:47-55.

Borghetti, M.; R. Giannini, and C. Nocentini. 1983. Indagini preliminari sulla variazione di alcuni caratteri del frutto in popolazioni di "Marrone Fiorentino". Monti e Boschi 1:49-52.

Breviglieri, N. 1955. Indagini ed osservazioni sulle migliori varietà italiane di Castagno. Centro di Studio Sul Castagno 2:27-164.

Chenet, B. 1983. Essai de classification de 15 varieties de chataigniers rassemblees dans le verger de la Grande Ferrade. Mémoire de fin d'etudes, Ecole Nationale Supèrieure Féminine d'Agronomie Rennes.

Fernández, J. 1984. Situación y perspectivas de los castañares tradicionales gallegos. Congreso Internacional del Castaño, Pontevedra 105-109.

Fernández, J. 1986. Los castañares de fruto españoles, avances e investigaciones en curso sobre el castaño. I Congreso Español de Frutos Secos, Tarragona 329-342.

Fernández, J. 1987. El castaño de fruto y las necesidades de divulgación, experimentación e investigación. Fruticultura Profesional 11: 109-114.

Fernández, J. and S. Pereira. 1993. Inventario y distribución de los cultivares tradicionales de Castaño (Castanea sativa Mill.) en Galicia. Istituto Nacional de Investigación y Tecnología Agraria y Alimentaria, Ministerio de Agricultura, Pesca y Alimentación.

Fernández, J., S. Pereira, and E. Miranda. 1993. Selección, identificación y esquema de producción de clones híbridos de Castanea sativa Mill. y C. crenata Sieb. et Zucc. o C. mollissima Blume para producción de madera o fruto. I Congreso Forestal de Lourizán, Pontevedra. 
Goodman, M.M. 1972. Distance analysis in biology. Systematic Zool. 21:174-186.

Goodman, M.M. 1973. Genetic distances: Measuring dissimilarity among populations. Yearbook Physical Anthropol. 17:1-38.

Goodman, M.M. and Mck. Bird. 1977. The races of maize: IV. Tentative grouping of 219 latin american races. Econ. Bot. 31:204-221.

Hidalgo, L. 1980. Caracterización macrofísica del ecosistema medioplanta en los viñedos españoles. MAPA, Serie Producción Vegetal 27 30 .

Hilling, K.W. and A. Iezzoni. 1988. Multivariate analysis in a sour cherry germplasm collection. J. Amer. Soc. Hort. Sci. 113:928-934.

Hussaini, S.H., M.M. Goodman, and D.H. Timothy. 1977. Multivariate analysis and the geographical distribution of the world collection of finger millet. Crop. Sci. 17:257-263.

Justo, M.J. and M.L. Almez. 1991. Fontes Documentais da Universidade de Santiago de Compostela. Pergameos da Serie do Arquivo Histórico Universitario. Anos 1237/1537. Diplomática, Consello da Cultura Galega. Documentos numeros 31 y 301 .

Kaufman, L. and P.J. Rosseeuw. 1990. Finding groups in data: An introduction to cluster analysis. Wiley, New York.

Kempthorne, O. 1969. An Introduction to Genetic Statistics. Wiley, Iowa. Llauradó, M. and J. Moreno-González. 1993. Classification of northern spanish populations of maize by methods of numerical taxonomy. I. Morphological traits. Maydica 38:15-21.

Ministerio de Agricultura, Pesca y Alimentación, 1980. Las Frondosas en el Primer Inventario Forestal Nacional. MAPA, Madrid.

Martin, G.B. and M.N. Adams. 1987. Landraces of Phaseolus vulgaris (Fabaceae) in Northern Malawi, I. Regional variation. Econ. Bot. 41:190-203.

Oliveira, J.A. and G. Charmet. 1992. Genotype by environment interaction in Lolium perenne: Grouping wild populations by cluster analysis. Invest. Agr. Prod. Prot. Veg. 7(2):117-128.

Pereira, S. 1994. Caracterización y selección de cultivares tradicionales de Castanea sativa Mill. en Galicia. PhD thesis, Universidad Politécnica de Madrid.

Pereira, S., J. Fernández, and J. Moreno-González (1995). Classification of Northwestern Spanish cultivars of chestnut. II. Isoenzyme traits. J. Amer. Soc. Hort. Sci. (In press.)

Pérez-Gonzales, S. 1992. Associations among morphological and phenological characters representing apricot germplasm in Central Mexico. J. Amer. Soc. Hort. Sci. 117:486-490.

Pérez, S., S. Montes, and C. Mejía. 1993. Analysis of peach germplasm in Mexico. J. Amer. Soc. Hort. Sci. 118:519-524.

Rubin, J. 1967. Optimal classification into groups. An approach for solving the taxonomy problem. J. Theoret. Biol. 15:103-144.

Sneath, P.H.A. and R.R. Sokal. 1973. Numerical taxonomy. W.H., San Francisco.

International Union for the Protection of New Varieties of Plants. 1988. Draft guidelines for the conduct of tests for distinctness, homogeneity and stability (CHESTNUT). TG/124/1(proj.). 